\title{
DocumentaÇ̃̃o
}




\section{Uma carta jesuíta de 1621}

Jean Marcel Carvalho França ${ }^{1}$

\section{Introdução}

A Europa conheceu, entre a metade do século XVI e o final do século XVIII, uma verdadeira enxurrada de escritos dos jesuítas que missionavam pelo mundo, escritos publicados em grandes crônicas gerais, em pequenos opúsculos ou em grandes coletâneas editadas pelos discípulos de Loyola baseados, sobretudo, na Itália e na França. Os exemplos são inúmeros. Em 1552, em Roma, começa a vir a público a série Avisi Particolari delle Indie di Portugallo..., com missivas dos jesuítas instalados nas possessões portuguesas de além-mar a oriente e a ocidente. Em 1578, sai a Lettres du Jappon, Peru et Brasil envoyées au R. P. General de la Société de Jesus, uma das tantas obras do gênero - em geral publicadas simultaneamente em italiano e francês - que reuniam cartas de missionários da Companhia espalhados pelo mundo. Logo no alvorecer do século XVII, entre 1604 e 1608, o padre jesuíta Pierre du Jarric publica, em Bordeaux, a importante Histoire des choses memorables, uma coletânea de cartas em três volumes, escritas por missionários jesuítas espalhados pelas possessões portuguesas nas Índias Ocidentais e Orientais. Em 1636, na Antuérpia, outro jesuíta, Nicolo Duran, publica uma volumosa carta ânua da província do Paraguai. Relativa à mesma província é a Historia provinciae Paraquariae Societatis Jesus, uma longa apologia da atuação jesuítica na região, escrita pelo padre Nicolas du Toict em 1673 - Du Toict viveu 31 anos no Paraguai. Logo no início do século XVIII, em 1703, tem início a edição da mais portentosa coletânea de cartas jesuítas entregue ao público europeu do período, a Lettres édifiantes et curieuses écrites des missions étrangères par quelques missionnaires de la Compagnie de Jésus, coleção de 34 volumes, publicada em Paris, entre 1703 e 1776, por Nicolas Le Clerc. Menos volumosa, mas igualmente significativa é a Der Neue

1 Jean Marcel Carvalho França é professor da Universidade Estadual Paulista Júlio de Mesquita Filho (Unesp) e Livre-docente em História do Brasil pela mesma Universidade, com a tese $A$ construção do Brasil na literatura de viagem dos séculos XVI, XVII e XVIII. É autor, entre outros livros, de Literatura e sociedade no Rio de Janeiro Oitocentista. Rio de Janeiro: Imprensa Nacional/Casa da Moeda, 1999; Visões do Rio de Janeiro colonial. Rio de Janeiro: José Olympio, 2ooo; Mulheres viajantes no Brasil. Rio de Janeiro: José Olympio, 2008 e co-autor de Andanças pelo Brasil colonial. São Paulo: Editora da Unesp, 20og. E-mail: jsfranca@uol.com.br 
Weltbott..., coletânea organizada pelo jesuíta Joseph Stocklein e publicada em Grätz e em Augsburg, entre 1728 e 1761².

Haveria, ainda, muitos outros escritos a adicionar a essa sintética lista: pequenos opúsculos contendo umas poucas cartas de um mesmo missionário (Niel, Labbé, Margat, Ignace Chomé, Cattaneo Gaetano, Guillaume d'Étré, etc.); cartas ânuas dos colégios espalhados pelo mundo; biografias de membros da ordem; histórias gerais das suas ações missionárias no além-mar - como a conhecida Crônica da Companhia de Jesus do Estado do Brasil (1668), do padre Simão de Vasconcelos. Em suma, uma longa e variada série de textos impressos, que teve papel nada desprezível na divulgação do Novo Mundo entre os homens do Velho Mundo.

Em meio a tamanha produção escrita, as cartas ocuparam um papel sobremodo importante. Divulgadas amplamente pela Europa culta, lidas e reproduzidas pelos sábios, as epístolas jesuítas (as ânuas e as individuais) tornaram-se uma referência incontornável para os que queriam saber mais sobre o Novo Mundo. O Brasil estreou cedo no gênero. Entre 1551 e 1555, foram editadas em Portugal duas obras contendo informações sobre a terra do Brasil, enviadas por missionários. A primeira, Copias de unas cartas enbiadas del Brasil, editada em língua espanhola, na cidade de Coimbra, em 1551, continha uma série de cartas dos jesuítas que desembarcaram com Tomé de Sousa na Bahia, em 1549: Manuel da Nóbrega, Antônio Pires, Afonso Brás, João de Azpicueta Navarro e Leonardo Nunes. Tais cartas, as primeiras remetidas da América pelos membros da Companhia de Jesus, reapareceram em italiano, em 1552, na mencionada Avisi particolari delle Indie di Portugallo. Em 1555, foi a vez do Copia de unas cartas de algunos padres e hermanos dela compañia de Jesus, livro publicado também em Coimbra e também em espanhol, que trazia cartas enviadas pelos discípulos de Loyola, baseados em Goa e Malaca, e as missivas de Pedro Correia, José Anchieta e João de Azpicueta Navarro, enviadas do Brasil ${ }^{3}$.

Depois das publicações coimbrãs, no entanto - editadas em língua espanhola -, a vasta correspondência jesuíta vinda do Brasil durante os dois séculos compreendidos entre o desembarque de Manuel da Nóbrega

2 Uma lista bastante completa da correspondência jesuíta publicada na Europa entre os séculos XVI e XVIII pode ser encontrada em: DUVIOLS, Jean-Paul. L'Amérique espagnole vue et rêvée: les livres de voyages de Christophe Colomb à Bougainville. Paris: Promodis, 1985. p. 333-481. Também incontornáveis são os livros: LEITE, Serafim. História da Companhia de Jesus no Brasil. Belo Horizonte: Itatiaia, 2oo6, vols. VIII e IX e RODRIGUES, José Honório. História da História do Brasil: historiografia colonial. São Paulo: Nacional, 2. ed., 1979. p. 249-296.

3 HUE, Sheila Moura. Primeiras cartas do Brasil (I55I-I555). Rio de Janeiro: Jorge Zahar, 2006. 
(1549) e a expulsão da Companhia dos domínios portugueses da América (1759) teve pouquíssimas edições em Portugal ou na língua de Camões ${ }^{4}$. Destarte, lamentavelmente, não se deveu ao empenho português a sua divulgação pela Europa, ao contrário, tal propagação, que não é nada insignificante, e teve impacto considerável na construção do Brasil e dos seus habitantes no repertório intelectual europeu durante o período, deu-se graças às prensas das cidades italianas e, em alguma medida, também àquelas instaladas na França - onde as cartas publicadas em italiano e latim eram traduzidas para a língua local e reunidas em coletâneas. Foi, pois, sobretudo, por meio de compilações não portuguesas, como a citada Avisi Particolari delle Indie di Portugallo ou, como a também já referida, Histoire des choses memorables, do jesuíta Pierre Du Jarric, que o Velho Mundo tomou contato com a perspectiva dos discípulos de Loyola acerca do ainda pouco conhecido Brasil.

O documento que o leitor encontrará a seguir é proveniente de uma dessas apreciadas obras que divulgavam para o curioso e ainda pouco extenso público leitor da Europa o empenhado trabalho missionário da Companhia no além-mar. Trata-se de uma carta ânua redigida pelo missionário jesuíta Manuel de Araújo, a mando do então reitor do Colégio da Bahia, o renomado Fernão Cardim. A carta informa ao Geral da Companhia em Roma, Mutio Vitelleschi, acerca do estado dos colégios e das residências da Bahia, Rio de Janeiro, Espírito Santo, Santos, Piratininga e Pernambuco, em 1621.

Poucas são as informações disponíveis sobre o autor da carta, o mencionado Manuel de Araújo ${ }^{5}$. Nascido na cidade de Viana do Castelo, ao norte de Portugal, em 1590, Araújo entrou para a Companhia em 1608 e tomou votos na Bahia. Até 1619, encontrava-se na aldeia de Escada, em Pernambuco, onde aprendeu a língua tupi e auxiliou o conhecido missionário Luiz Figueira. Em 1620, retornou à Bahia e, em 1621, já ocupava o cargo de Mestre de Humanidades do Colégio Jesuíta de Salvador, então sob a direção de Fernão Cardim. Em 1631, quando da invasão holandesa

4. A esmagadora maioria das cartas jesuítas enviadas do Brasil foram publicadas tardiamente em português, já no século XX. A este respeito, consultar: LEITE, Serafim (Org.). Cartas dos primeiros jesuitas do Brasil. São Paulo: Comissão do IV centenário da cidade de São Paulo, 1954, 3 vols.; (Org.). Novas cartas jesuitas, São Paulo: Nacional, 1940 e PEIXOTO, Afrânio (Org.). Cartas jesuíticas. Belo Horizonte/ São Paulo: Itatiaia/ Edusp, 2. ed., 1988, 3 vols.

5 Mais detalhes sobre a vida de Manuel de Araújo, ver: LEITE, Serafim. História da Companhia de Jesus no Brasil. op. cit. p. 64, e CARDIM, Fernão. Tratados da terra e gente do Brasil. Introdução e notas de Rodolfo Garcia. Belo Horizonte/ São Paulo: Itatiaia/ Edusp, 1980. p. 16. 
de Pernambuco, o missionário encontrava-se no Colégio de Olinda e, em 1639, por razões desconhecidas, abandonou a Companhia.

A carta ânua de Araújo, embora tenha sido muito citada por Serafim Leite na detalhada História da Companhia de Jesus no Brasil, ainda não havia sido vertida para o português. A sua publicação deu-se, pela primeira vez, em 1627, em italiano, em uma coletânea intitulada Lettere annue d'Etiopia, Malabar, Brasil e Goa. Em 1628, a obra foi traduzida para o francês por "um padre da Companhia" - como vem indicado na capa - com o título Histoire de ce qui s'est passé en Ethiopie, Malabar, Brésil, et les Indes Orientales. Tirée des lettres ecrites és années 1620, jusques à 1624. Ambas as publicações não foram reeditadas. 


\section{Extrato das cartas enviadas do Brasil no ano de $1621^{6}$}

Há 187 dos nossos espalhados aqui e ali pelo Brasil, 65 dos quais são padres e o restante, irmãos, aí compreendidos 21 noviços.

\section{O Colégio da Bahia e de Castelo}

O Colégio da Bahia e mais quatro residências abrigaram, este ano, trinta dos nossos. Os padres Domingos de Sequeira, Jerônimo Veloso, Paulo de Carvalho e o irmão Diogo Soares (um noviço) faleceram. O padre Paulo de Carvalho morreu no dia 15 de maio, antes mesmo de completar dois anos de permanência no Brasil. Ele nasceu em Évora, cidade de Portugal, e com 15 anos entrou para a Companhia, onde sempre demonstrou ser um homem de espírito largo, versado em todas as ciências, humilde e inimigo das honras aparentes. Era admirável ver um homem assaz importante e célebre nas grandes universidades fazer tão pouco caso de sua reputação. Jamais pudemos apontar na sua conduta um único sinal de vaidade. Carvalho mortificava-se quando, por ocasião das cerimônias públicas, tinha de portar o seu gorro de doutor. Sua única alegria era ir para as vilas ensinar às crianças e aos pastores. Dizia que a tristeza e o descontentamento que lhe causavam as pessoas doutas e os aplausos arrancados em lugares importantes transformavam-se em mel e açúcar quando se encontrava entre os pobres aldeões e a gente rústica, gente desprezada por todos. Dizia também que, graças a uma luz divina, via com clareza que a vida cá embaixo não passava de indignidade, vilania e baixeza. E o que falar, então, de seu ímpeto para a autopunição? Carvalho mais não fazia do que penitências, de sua boca só saiam palavras sobre isso e suas exortações eram sempre em tal direção. De compleição delicada e débil, seus superiores esforçavam-se para que nada lhe faltasse, mas ele recusava tudo. Foi por meio de sua insistência que obteve permissão para trabalhar nas missões das aldeias, o que conseguiu somente depois de inúmeras recusas. Durante suas viagens,

6 Quanto à edição utilizada, há pequenas diferenças entre as edições italiana e francesa. Optamos, malgrado a semelhança, por consultar ambas para a presente tradução: DARAYO, Michele (Luís Baralho de Araújo). Estratto di alcune cose escritte bal Brasile nell'anno 1621. In: VITELLESCHI, Mutio. Lettere annue d'Etiopia, Malabar, Brasil e Goa. Roma: Francesco Corbelletti, 1627. p. 117-138 e DARAYO, Michele. Extraict des lettres envoyées du Brasil l'an 1621. Le college et la residence du Rio de Janeiro. In: VITELLESCHI, Mutio. Histoire de ce qui s'est passé en Ethiopie, Malabar, Brésil, et es Indes Orientales. Tirée des lettres ecrites és années I6ro, jusques à 1624. Paris: Sebastien Cramoise, 1628. p. 149-170. 
Carvalho muitas vezes viu e vivenciou os poderes da providência Divina, mas narrarei somente um caso. Certa vez, indo pregar, no meio do caminho entre uma aldeia e outra, uma tempestade repentina alagou toda a região. Ao retornar para casa, o Superior perguntou-lhe se não tinha ficado encharcado. Carvalho respondeu que não, e realmente seu hábito parecia bem seco. Como todos se espantaram, ele complementou: "Não vos inquieteis, pois Deus permite que os corajosos se molhem, mas a mim, que sou débil e doente, ele não quis molhar."

Carvalho muito se esforçava por aprender a língua brasileira, língua extremamente difícil e espinhosa, mostrando a todos os nossos que é preciso estudar com coragem as coisas necessárias para auxiliar as almas - exemplo muito edificante. Um dia, Carvalho foi enviado para ouvir a confissão de uma pobre mulher que morria. Por mais que a mulher se esforçasse, ele não conseguiu entender uma única palavra que saía de sua boca. Vendo que o fim da pobre se aproximava, ele deu a ela a absolvição mediante condições. Logo em seguida, a mulher expirou e o padre retornou para a residência. Ao entrar em seu quarto, Carvalho cerrou as janelas e pôs-se a chorar copiosamente. Entrementes, soou o aviso do refeitório e todos se dirigiram para lá, exceto o padre. Um seu companheiro, notando sua ausência, dirigiu-se ao seu quarto para buscá-lo, encontrando-o de joelhos, com as mãos juntas, chorando calorosas lágrimas e suspirando, em meio a soluços, com os olhos voltados para um crucifixo. O irmão, espantado com o espetáculo, perguntou-lhe o que se passava. "Oh! Meu irmão, clamo a Deus que eu possa trocar todo o saber que adquiri por meio dos meus estudos pelo conhecimento da língua desse país. Teria dado qualquer coisa, por mais valiosa e pessoal que fosse, para poder ajudar a pobre serva de Deus que morreu hoje em minhas mãos tentando me fazer entender os seus pecados.” $\mathrm{O}$ irmão tentou consolá-lo, mas foi em vão, e implorou-lhe que o seguisse à mesa, pois já se fazia tarde. Todavia, ninguém conseguiu fazê-lo comer até o dia seguinte, quando a debilidade obrigou-o a tal.

Dois dias antes de morrer, já doente, Carvalho recebeu a extremaunção. Notamos que ele, que vivera de maneira santa neste mundo, não tinha qualquer temor da morte. Ele mandou chamar o seu professor de língua brasileira e interrogou-lhe muito seriamente acerca de algumas dúvidas referentes a esse idioma, assegurando-o de que sempre experimentara mais prazer no estudo de tal língua do que nas sofisticadas especulações que desenvolvera. Era notável como, em apenas um ano, ele avançara tanto no estudo de uma língua repleta de palavras difíceis de guardar na memória e já fosse capaz de falá-la em público. Tal avanço era sempre atribuído por ele ao padre Anchieta, seu especial intercessor e aquele que o introduzira e o conduzira nesta empresa; e para 
atingir o cúmulo da excelência, ele praticava a oração no mais elevado grau. Esquecer-se de beber, comer ou mesmo dormir era coisa extremamente comum de acontecer. Frequentemente, Carvalho ficava tão absorto, que não respondia a ninguém, por mais que o chamassem. Apegado ao extremo à Nossa Senhora, ele a tinha como sua verdadeira mãe e como a Rainha da Misericórdia, dedicando-se inteiramente ao seu serviço. A devoção que tinha à sagrada humanidade de Nosso Senhor era inimaginável. Em suma, as virtudes e ações deste grande servidor de Deus eram em tão grande número e tão singulares que é melhor silenciar sobre as mesmas do que contá-las pela metade, obscurecendo a sua luz.

À morte do padre Carvalho, seguiu-se o passamento do padre Domingos de Sequeira, professo dos quatro votos, nascido em Ilhéus, um burgo da diocese da Bahia. Sequeira tinha 57 anos, quarenta dos quais inteiramente dedicados ao serviço da Companhia, a maior parte no Brasil. Ele passou um ano inteiro padecendo de dores imensas, após o que passou suavemente para a outra vida. Sua morte deu-se no dia 15 de maio, como previra há bastante tempo o padre José de Anchieta.

O padre Jerônimo Veloso, natural de Lisboa, morreu pouco depois, com a idade de 100 anos. Veloso dedicou 65 anos à Companhia e morreu no dia 7 de agosto tal como tinha vivido, como um bom religioso.

O último que perdemos foi o irmão Diogo Soares, um noviço flamengo, nascido em Anvers, que se encontrava entre nós há somente nove meses e que, vivendo em consonância com a religião, foi chamado por Deus para desfrutar da recompensa pelos seus méritos. Antes de ser religioso, ele jejuava três vezes por semana e se penitenciava por todas as coisas.

Os outros padres da Companhia que não foram atacados por doenças têm se dedicado intensamente ao cultivo da vinha de Nosso Senhor: uma etíope converteu-se após a confissão e muitos abandonaram as suas concubinas. Havia duas pessoas que, há bastante tempo, travavam uma disputa acerca dos limites de uma plantação de canade-açúcar. Depois de tomarem por árbitro um dos nossos, a disputa teve termo. Outros, que há muito eram inimigos capitais, apaziguaram os seus ânimos e, como prova de amizade, acertaram um casamento. Um outro, ainda, corrigiu, por meio de uma verdadeira penitência, as práticas sacrílegas que cultivava há quarenta anos.

A glória do padre José de Anchieta, a cada dia, se expande mais e mais por meio de milagres, um dos quais passarei a narrar. Um jovem descobriu que tinha um tumor na garganta e ouviu dos médicos que era necessário extraí-lo. Um dia antes de fazê-lo, o rapaz mandou chamar um dos nossos padres para consolá-lo. Este levou-lhe uma relíquia do padre Anchieta e, apresentando-a ao doente, exortou-o a entregar-se ao servidor de Deus. $\mathrm{O}$ 
rapaz tomou a relíquia em suas mãos e devotamente a colocou sobre o seu mal. Eis que subitamente o doente perdeu os sentidos, coisa que jamais lhe ocorrera antes. As pessoas presentes, sem poderem se conter, puseram-se a chorar de satisfação e alegria; até mesmo os médicos disseram em alta voz, milagre! O pobre rapaz, no entanto, pouco pôde aproveitar da graça alcançada, pois morreu poucos dias depois de outra doença.

Quatro mulheres em trabalho de parto, que corriam risco de morrer, depois de beberem água de um lugar onde tinham sido banhadas as relíquias do padre José de Anchieta, ficaram totalmente curadas.

O padre Provincial, no ano corrente, estabeleceu mais três novas missões. Uma delas no Maranhão, a pedido de Dom Diogo Mendonça Furtado, que doou para o empreendimento 250 escudos de ouro. Foi enviado para o local o padre Luiz Figueira, conhecido predicador e um dos primeiros que vieram para o Brasil, e o padre Benedito Amodei, siciliano natural de Bivona. Ambos são zelosos e amantes da penitência. A segunda missão foi fundada a pedido do Presidente do Senado da Bahia, a 200 léguas desta cidade. É bastante difícil lá chegar, pois o caminho, que atravessa somente florestas e desertos, é bastante cansativo e não dispõe de nenhum recurso para a sobrevivência, nem mesmo água. O padre Pero de Castilho, que compreende muito bem a língua dos índios, e o padre José da Costa, siciliano natural de Trepane, foram enviados para lá. A terceira missão está localizada em Porto Seguro, onde os padres Mateus de Aguiar e Gabriel de Miranda construíram uma nova Residência. Esperamos colher alguns frutos dessas missões no próximo ano.

\section{O Colégio de São Sebastião do Rio de Janeiro}

Em razão de uns ventos que sopram por aqui em determinadas épocas do ano, ventos que tornam o mar impraticável, a carta ânua desse Colégio tratará de coisas que tiveram lugar no ano passado.

Neste Colégio estão 27 membros da Companhia, dos quais doze padres e quinze irmãos. Todos passam bem, com a graça de Deus, e empenham-se com vigor no divino serviço. Diariamente, ao nascer do dia, mesmo nos festivos, eles fiscalizam o trabalho dos escravos e de seus feitores. Ao entardecer, depois de repetirem as tarefas da manhã, saem pelas ruas e praças públicas e esforçam-se por conseguir algum dinheiro. Essa santa cobiça tem atraído para a Companhia a simpatia de todos. A prova disso foi-nos dada por quatro senhores que, depois de jurarem de morte uns aos outros, se reconciliaram graças a uma rápida conversa que um de nossos padres teve com eles. $\mathrm{O}$ mesmo se deu com um magistrado da cidade. Tendo sido 
ofendido publicamente, ele resolveu vingar-se do ofensor com toda severidade e dureza, só não procedendo dessa maneira graças à intervenção de um dos nossos. Depois de uma conversa, o magistrado não somente perdoou o agressor, como ainda se humilhou diante dele.

Mas os seculares não são os únicos simpáticos à Companhia. Tal sentimento é compartilhado também pelos religiosos e mesmo pelos eclesiásticos, especialmente pelo Senhor Reverendíssimo Prelado, aqui chamado de Administrador. Relatarei um testemunho dessa afeição generalizada. Um malfeitor, que assassinara um homem, escapou das mãos da justiça e refugiou-se em um convento de religiosos. Os oficiais da justiça vieram ao seu encalço, agarraram-no no claustro e, malgrado a intervenção dos religiosos, arrastaram-no à força. Os ditos religiosos, vendo a violência com que tratavam o malfeitor, resolveram exigir que respeitassem a imunidade da igreja. Os oficiais, ofendidos, voltaram-se para os servos de Deus e, com grande escárnio, disseram-lhes uma série de impropérios. A querela esquentou e surgiram ameaças de querimônias e excomunhões. Para ruína de muitos, os envolvidos estavam quase a se atracarem, quando alguns dos nossos intervieram e, para grande contentamento de todos, restabeleceram a concórdia entre as partes. Temos, frequentemente, visitado os pobres no hospital e lhes ofertado gordas esmolas.

Esse Colégio mantém três residências, as quais abrigam muitos portugueses. A Residência de São Lourenço é visitada pelos nossos a cada 15 dias. Nas outras, residem quatro religiosos, dois em cada casa.

No castelo de São Barnabé havia uma infiel que se dizia conhecedora dos mistérios da nossa fé. Ora, um dia, estando ela doente e temendo morrer, mandou chamar um dos nossos padres, deixou-se batizar e, pouco depois, ouvindo os doces nomes de Jesus e de Maria, expirou. Outro dos nossos foi chamado à casa de um português, que morava em um lugar assaz distante do castelo, para amparar uma senhora enferma. Lá chegando, encontrou-a quase moribunda e só teve tempo de confessá-la e prepará-la para a morte, morte que ela, redimida, enfrentou com tranquilidade.

A floresta de Goitacases, que está repleta de bárbaros e selvagens, comecou este ano a render alguns frutos de seu jardim de almas. E isso graças aos cuidados incessantes dos nossos. Os selvagens, hoje, não são mais tão reticentes em nos entregar suas crianças para que as batizemos. Das treze que nos entregaram, onze subiram ao céu. Dissemo-lhes, com o intuito de induzi-los a colaborar com o batismo, que aquelas que morreram, como tinham sido ungidas com água batismal, poderiam interceder por seus pais junto ao Senhor. Determinamos, em seguida, que um dos nossos desse sepultura a elas. O funeral teve até uma certa pompa. Dois dos padres da Companhia, devidamente paramentados, acompanhados por 
muitos índios, conduziram o cortejo à igreja, cortejo que seguia cantando, ao som de sinos, com os candelabros acesos. Os bárbaros se impressionaram muito com essa cerimônia e, desde então, passaram a nos entregar mais facilmente as suas crianças.

Passo agora a relatar as festas e os folguedos que se fizeram por ocasião da beatificação do padre Francisco Xavier. Logo que se soube da notícia de que o Papa Paulo V tinha declarado o padre beato, as manifestações de contentamento foram indescritíveis, pois todas as índias têm uma grande devoção por esse seu glorioso Apóstolo. No início da noite, começamos as festividades, espalhando, do alto do campanário da igreja, alguns sinais de alegria. O Colégio parecia em chamas, tamanha era a quantidade de luzes que o adornavam. Isso fez com que o povo viesse saber qual era a novidade. Depois de se informarem sobre o que se passava, todos deram graças a Deus, invocando em alta voz o beato Xavier. Tanto a nobreza quanto a populaça insistiram para que lêssemos o Breve da Beatificação, vindo de Roma. Nossos padres julgaram que a reivindicação era bastante justa e resolveram atendê-la sem restrições, fixando uma data para o pregador fazer a promulgação do Breve. O concurso de pessoas e o contentamento e a devoção que manifestaram foram imensos. À noite, os sentimentos da população ficaram ainda mais evidentes, pois quase todos os quarteirões da cidade estavam em festa. $\mathrm{O}$ bispo, que tinha uma especial devoção pelo bemaventurado padre e sempre demonstrara grande simpatia pela Companhia, não mediu esforços para expressar sua alegria. A festa que promoveu em sua igreja superou todas as demais da cidade. Tão grande era sua devoção pelo beato que chegou a fazer luminárias coloridas com as próprias mãos, as quais, depois de prontas, foram dispostas de um modo que pareciam formar uma belíssima coroa em torno da sua igreja. A decoração chamou a atenção de todos e deu muito o que falar. No dia da festa, o bispo celebrou a véspera, a qual contou com uma música excelente, executada por três coros de vozes e instrumentos, e terminou com uma procissão. A Igreja, neste dia, estava ricamente paramentada. Ao entardecer, toda a nobreza, montada em cavalos maravilhosamente ajaezados, apareceu na cidade e esforçou-se por se juntar ao regozijo público.

\section{A Missão do Espírito Santo e sua Residência}

Dezesseis dos nossos residem nesta região, parte na Missão, parte em quatro outras residências. Havia aí, em um certo burgo, uma mulher que estava às beiras da morte. Ela solicitou que um dos nossos padres a visitasse, para que pudesse se confessar. Depois de receber a absolvição, com 
o rosto molhado de lágrimas, a mulher disse aliviada: "Oh Meu Senhor! Vossa vontade seja feita, eu temia somente os pecados que praticara, mas agora estou tão consolada, que mal tenho palavras". Imediatamente, ela recebeu a extrema-unção, cerrou os olhos e morreu. O mesmo se passou com uma outra senhora, que assegurou ao padre ser seu maior desejo nesse mundo confessar-se uma vez mais antes de morrer.

Um doente que os médicos tinham desacreditado, tendo sido aconselhado por um dos nossos a beber da água proveniente de um lugar onde tinham sido banhadas as relíquias do beato José de Anchieta, curou-se na mesma hora.

\section{As Residências de Santos e de Piratininga}

Dez dos nossos religiosos ocupam essas duas Residências, encarregados de confessar, pregar, instruir e batizar. A notícia da beatificação do beato São Francisco Xavier, ao alcançar a Residência de Santos, despertou no coração do povo sentimentos de grande piedade. Comemorou-se a nova aqui mais do que em qualquer lugar do Japão. O governador doou uma quantidade inacreditável de pólvora para os fogos de artifício.

Os padres de Piratininga tomaram sob seus cuidados quatro aldeias de índios. Eles visitam-nas algumas vezes por ano e, com muitos bons resultados, pregam, confessam e catequizam. Dois dos nossos, estando em uma dessas aldeias, receberam a súbita visita de dezesseis selvagens, que saíram subitamente da mata e disseram que gostariam de aprender a religião dos filhos de Deus. Um dos nossos aproximou-se deles e lhes disse que a igreja era aberta a todos que quisessem entrar. Tais palavras parecem tê-los deixado bastante satisfeitos. Depois de ouvi-las, retiraram-se novamente para a mata, dizendo que iriam informar ao seu governante, o qual se encontrava bem distante dali. Deus realmente tenciona retirar esses povos da idolatria e fazê-los reconhecer a luz da verdade.

Um pagão da raça maramonin, vendo que sua vida estava em vias de se esgotar, mandou chamar um de nossos padres para batizá-lo. O padre, crendo que nada justificava tamanha pressa, catequizou-o, consolou-o e partiu, dizendo-lhe que o batizaria em outra ocasião. O pobre doente levantou-se como pôde do leito onde estava e, caminhando como um homem à beira da morte, deslocou-se até a residência do padre para suplicar ao religioso que o batizasse. $\mathrm{O}$ bom padre, ao ver tal cena, comoveu-se e resolveu batizá-lo. O doente expirou quase em seus braços. 


\section{O Colégio e a Residência de Pernambuco}

Trinta e cinco dos nossos estão instalados nas duas casas, sendo quinze padres e o restante irmãos, dois dos quais ensinam gramática às crianças. Os trabalhos, todavia, superam o número de obreiros. Assistimos aos etíopes de toda a nossa jurisdição. Eles têm o costume de se reunirem nas vilas e burgos para dançar, jogar e beber. Nos domingos, dois dos nossos saem pelas ruas, convidando-os a ouvir a Doutrina Cristã. Ainda que os resultados deixem muito a desejar, ao menos tal trabalho impede que os etíopes ofendam a Deus com as mil puerilidades e tolices que fazem.

Prega-se em toda parte, por aqui e nos arredores, o que tem resultado em muitas confissões gerais e grande quantidade de conversões. Muitas pessoas más, que armavam emboscadas para surpreender e matar os seus inimigos foram impedidas de assim proceder depois que os nossos intervieram. Nada direi sobre as esmolas que se têm recolhido para os hospitais e os necessitados e sobre as Congregações de Nossa Senhora e das Onze Mil Virgens, que vão muitíssimo bem.

Há doze dos nossos espalhados por cinco aldeias de índios, que aí pregam, catequizam e administram os Santos Sacramentos. A caridade desses religiosos ainda tem ido mais longe, pois eles têm dado de comer a muitos, na maior parte das vezes tirando de suas próprias bocas. A peste atacou violentamente aquelas plagas. Em um único mês, a doença matou setenta pessoas de um pobre burgo. Os nossos trabalharam como médicos, cirurgiões e criados, e ninguém morreu sem receber os Sacramentos.

Dois dos padres de Pernambuco excursionaram até um lugar denominado Rio Grande. Eles sofreram muitíssimo, em razão dos bárbaros da região, que não estavam acostumados a contatar com os nossos e eram terrivelmente viciosos e desonestos. Daí, os padres seguiram para uma vila de portugueses, onde, a pedido dos moradores, se detiveram por alguns dias. Nesse lugar, trabalharam para extirpar os abusos, os quais tinham alcançado tal estágio que, pode-se dizer, de cristãos os moradores locais só tinham conservado o nome. Eles correram ainda alguns burgos vizinhos, onde predicaram, catequizaram, confessaram, batizaram e auxiliaram na construção de três capelas em honra do grande Deus. Uma vez esgotado o tempo de sua missão, os padres, para grande pesar dos habitantes dos lugares por onde passaram, tiveram de retornar à sua residência.

Durante este ano, foram realizadas $40 \mathrm{mil}$ confissões ordinárias e 155 confissões gerais. Foram oficializados também 30.500 comunhões, 796 batismos e 473 casamentos católicos. Encerro aqui a minha carta, escrita da Bahia, em dezembro de 1621. 